\title{
Descriptive geometry as a tool for the development of future architects' imaginative abilities
}

\author{
Olga Melnikova ${ }^{1, *}$, and Svetlana Shuvalova ${ }^{2}$ \\ ${ }^{1}$ Department of Descriptive Geometry and Engineering Graphics, Saint Petersburg State University of \\ Architecture and Civil Engineering, 4 Vtoraya Krasnoarmeiskaya str., Saint Petersburg, Russia \\ ${ }^{2}$ Department of Descriptive Geometry and Engineering Graphics, Saint Petersburg State University of \\ Architecture and Civil Engineering, 4 Vtoraya Krasnoarmeiskaya str., Saint Petersburg, Russia
}

\begin{abstract}
The article gives a brief overview of the types of perspective. The importance of perspective's construction from the real point of view is noted. An attempt to clarify the significance of spatial thinking and creative imagination in teaching an architect's profession is made in this paper. The methods of descriptive geometry affecting the accuracy of visual clarity are determined. The importance of creative and professional characteristics of a student-architect and a practicing architect are examined. Students-architects and practicing architects with different working experience were presented as the respondents. The similarity in the designation of high importance of imagination and creative thinking in all groups of respondents in professional work was revealed.
\end{abstract}

\section{Introduction}

Descriptive geometry is a section of geometry in which different methods of threedimensional representation of objects on a flat surface are studied. It is one of the main disciplines in professional training of an architect. The course of descriptive geometry includes: methods of representation of three-dimensional objects on a plane; methods of graphic solutions of various geometric problems associated with original; basic principles of geometric shaping of surfaces; methods of increasing visibility and visual accuracy of the designed object's representation (perspective).

\subsection{History of perspective}

The origin of perspective images

Artists and architects have always faced a difficult task - to depict a three-dimensional object in a two-dimensional sketch or painting. In ancient and Medieval times, artists built the image intuitively, following visual impressions and common sense. First attempts of presentation of spatial forms on the flat surface belong to the ancient period of Egypt and Assyria temples construction. The first information about projection representation and

\footnotetext{
* Corresponding author: melnikova.gasu@yahoo.com
} 
perspective appeared in antique period. Greek geometer Euclid's essay (which doesn't exist now) is mentioned in the treatise of the Roman architect Vitruvius "Ten books on architecture». It sets out the rules for the implementation of plans and front elevation, but without a projection connection between them. In that essay Euclid notifies initial findings not only about the project which has to consist of a plane and front elevation but mentions the "central projection", "perspective point" and "point of view" - the concepts necessary for the construction of a visual image.

In contrast to the period of Middle Ages, which did not leave any significant works on the image representation theory, Renaissance era was marked by the rapid bloom of architecture, painting, sculpture in many European countries, which created the conditions for the development of theoretical foundations of perspective on geometric basis. That was when terms such as Central projection, picture plane, distance, main point, horizon line, remote point appear. One of the first who successfully applied perspective in his work, was an Italian scientist and architect Filippo Brunelleschi (1377-1446). Leon Batista Alberti (1404-1472), an outstanding scientist and art theorist, in his treatises "on painting" and " on architecture" summarized and developed artistic and professional experience of Brunelleschi and other masters in the field; he offered a way to build a perspective using a grid. The treatise on the perspective of the brilliant scientist, engineer and artist Leonardo da Vinci (1452-1519) provides not only options for the use of perspective images, but also contains information about the air perspective and the light and shadow theory.

Present perspective

Nowadays the construction of a perspective image is carried out in different ways, with different positions of the horizon line, point and angle of view. Depending on the design stage of an object, the perspective can solve the following tasks: to identify the gaps in architectural solution in time or to show the advantages of an already completed project. The teachers of the faculty of architecture in SP SUACE took part in the research, and they noted that students use a two-point linear perspective in the construction of a visual image more often (in $92 \%$ of cases), sometimes with the lower point of view. This perspective most clearly shows the advantages of the object and gives it a "dramatic" effect. But the first and essential condition for choosing a point of view is its reality and it must be chosen in the light of current situation. The choice of an unreal point of view can lead to the fact that there will be significant differences between the architect's intention and the impression that the building produces on the user.

The choice of a particular method depends not only on the type of object and its threedimensional structure, but also on the task that the architect solves at the moment. Our research shows that students-architects think that the qualitative presentation of their project is the most important task; that is, they need to show the advantages of the final project. In their opinion, the most important skills for successful work are the creative abilities. Practicing architects note the importance of the quality of professional design work, the quality of architectural solutions in particular, not the presentation; and they also realize their responsibility to society [table 2].

\subsection{The architect's activities in different historical epochs}

Organization of space is the main subject of professional practice for the architect in all periods of history, "the space has always been the core of architecture of all times, as in buildings, so in cities" [1]. The ideas of a primitive man about the surrounding space were formed in the conditions when the main problem of mankind was survival. Since the beginning of time people needed shelter from natural disasters, hostile enemies and predators. Many millennia passed and, with the beginning of the decomposition of the primitive society, a man moved from the use of shelters provided by nature, to the production of homes 
that meet its increased needs. Architecture appears only when there are three factors taken together: the image of the building, the awareness of its stability or durability and how it is inscribed in the surrounding space. [2] Despite the construction of a number of megalithic structures, it is unlikely that the ancient man was concerned about all three factors in the aggregate, so neither architecture itself, nor the architect as a specialist didn't exist in those days, but there was only the origin, the first hints at architectural work.

After people mastered basic construction skills, learned to build first primitive buildings, and then more complex structures, it became necessary to have an idea of the final version of the structure, to have a complete image of the construction object. This meant that it was time to apply the drawings first, and then the sketches, using the set of symbols and signs accumulated by that time. Although a drawing as a means of information transfer appeared long before the writing system, the appearance of the first drawings is directly related to the increasing complexity of buildings. Consequently, there were the first "specialists", able to convey their idea to all participants of construction, and then mastered the main skill - a graphical way of information transmission.

Throughout the history of mankind, ideas about the surrounding space have developed in interaction with the human way of life, the form of activity, the current worldview and in close dependence on the form of consciousness [3]. In the mythological consciousness of Ancient Greece, and then of Ancient Rome, the unity of myth and reality was preserved. The emergence of the term "tekne" ("art") is equally applicable to various forms of activities: craft and the fine arts [3]. The integrality of the world perception was reflected in the teachings of the Pythagorean school, which main position was that everything should be harmonious. The concept of harmony included some dialectical elements (chaos and order), as well as structure, proportionality, perfection. "In Ancient Greece, for example, the architectural forms of temples were associated with parts of the human body. It was natural for the temples to be dedicated to gods of flesh and blood, representing the external image of the ideal person. It was not the imitation of human forms, but the representation of human body ideal proportions" [4]. Despite the fact that in ancient world not only visual art was developed, but also poetry and music, it was "visual" art that had a predominant role in the world cognition. Analysis of Greco-Roman ancient texts indicate that "only vision sense was considered in the ancient world the cognitive process that is able to show us this thing, as it is this thing" [3].

Renaissance era is associated with the process of decay of feudalism and establishment of bourgeois relations. The "dark" religious ideology of the middle Ages was replaced by the heritage of Antiquity - humanism, with an emphasis on social life and pleasure. Renaissance thinkers develop models of ideal cities considering the numerous needs of man; along with it the rules of perspective constructions, the theory of chiaroscuro and composition are formed. Art, literature, painting, architecture - all this was means to solve not only moral, aesthetic, but also psychological problems of man and is reflected in the architecture of public buildings, palaces, parks, country estates. The heritage of antiquity in the Renaissance is expressed not only in the reproduction of some ideas - the architectural order (post-beam system) finds a new interpretation and is used already in buildings construction in a wider range. The main purpose of the architecture "convenience-durability-beauty" is finally formed and expressed in every outstanding building of that era.

Renaissance era described a mathematically rigorous teaching about the ways of threedimensional representation for the first time, calling it a system of perspective. However, later, with the help of mathematical calculations, it was proved that an adequate spatial representation, in all details corresponding with the visual perception of the spatial image, on a flat surface is impossible. This means that none of scientific perspective systems can serve as a representation model. Nevertheless, in the history of fine arts there are several 
types of perspectives: direct linear perspective, reverse linear, panoramic, spherical, dome, tonal, airial, perceptual, axonometric. The article discusses some of them.

\subsection{Types of perspective images}

Linear perspective. Type of perspective, designed for a fixed point of view and implies one vanishing point on the horizon line (objects are reduced proportionally as they move away from the foreground). The theory of linear perspective was developed in the Renaissance, based on the simple laws of optics and perfectly confirmed by practice. Displaying space on the flat surface by the camera obscura is completely the subject to the laws of linear perspective. For a long period of time linear perspective was recognized as the only true reflection of the world in the sketch.

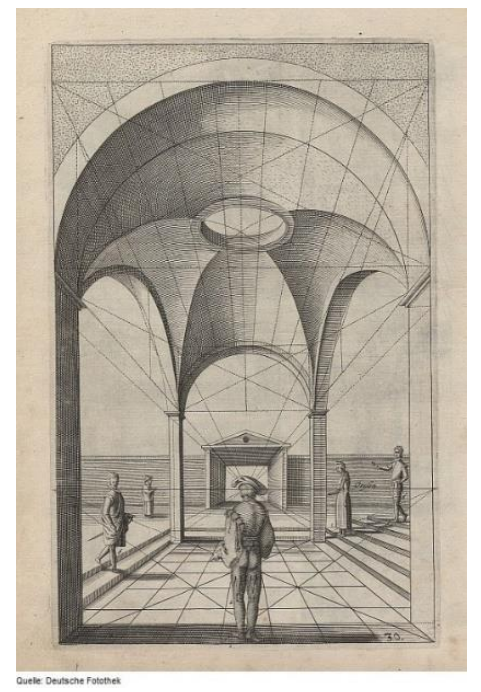

Fig. 1. Linear perspective

Given that a linear perspective is an image represented on a flat surface, the surface can be positioned vertically, obliquely, and horizontally depending on the purpose of perspective images. The vertical plane on which the images are built with the help of linear perspective is used to create paintings (easel painting) and wall panels (on the wall indoors or outside the house, mainly at its end walls). Construction of perspective images on inclined surface is used in monumental painting, which is painting on inclined friezes inside the palace buildings and cathedrals. In easel painting perspective images of tall buildings are represented on the inclined surface from a close distance; and architectural objects of the urban landscape are represented from a bird's eye view. Construction of perspective images on the horizontal surface is used for ceilings painting (plafonds), such images are built in perspective on the horizontal plane of the ceiling, called the plafond perspective.

Reverse perspective. Perspective view, used in Byzantine and ancient Russian painting, in which depicted objects appear increased as they recede from the viewer, the picture has several horizons and points of view, and other features. In the reverse perspective, the objects expand when they recede from the viewer, as if the center of the lines is not on the horizon, but inside the viewer.

The reverse perspective came into existence in the late antique and medieval art (miniature, icon, mural, mosaic) both in Western European and Byzantine group of countries. Among the reasons for the reverse perspective phenomenon, the simplest and most obvious for critics was the inability of artists to portray the world as it is seen by the observer. Thus, 
this perspective system was considered the wrong method, and the term of perspective false. However, academician B. V. Rautenbach, arguing against this misconception about the reverse perspective, shows that in certain conditions (at a small distance) the human eye perceives the image not in a straight line, but in the reverse perspective, which phenomenon, thus, lies in the sphere of perception itself [5].

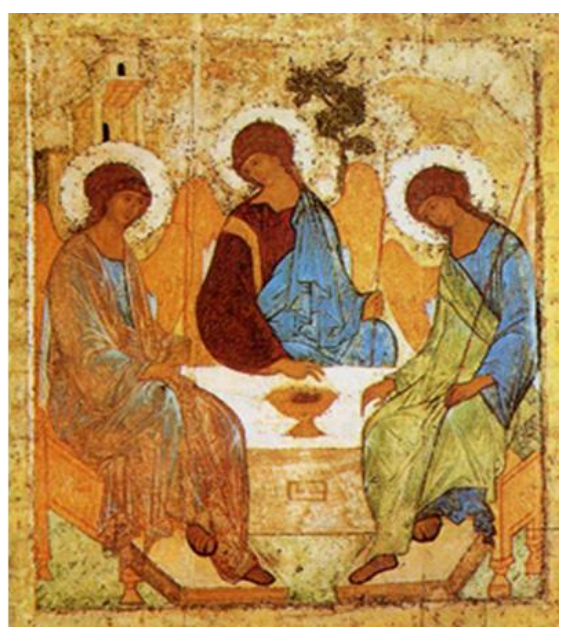

Fig. 2. Reverse perspective

For example, the reverse perspective is quite "natural" for children's perception. A characteristic feature of children's consciousness is the animation of matter, and the reverse perspective contributes to it. Therefore, cartoon characters come to life in the children's eyes, just as images and faces from icons come to life in the vision of adults.

Tonal and aerial perspective. Sfumato. Aerial perspective is characterized by the disappearance of clarity of the objects' outlines as they recede from the observer's eye. In this case, the background is characterized by decrease in color saturation (color loses its brightness, the contrasts of light and shade are softened), thus, the depth seems darker than the foreground.

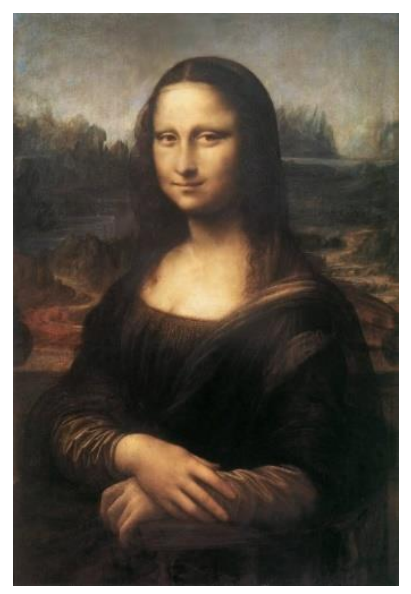

Fig. 3. Sfumato

Tonal perspective is a change in the color and tone of the object, decreasing its contrast characteristics, suppression in removing deep into space. Leonardo da Vinci was the first to justify the principles of tonal perspective. 
Leonardo da Vinci is also the founder of the sfumato technique in the graphic arts. The term "sfumato" refers to the technique of oil painting, in which the tone and color palette are arranged in such way that flow into each other without visible edges and borders. At the same time, it looks like there is the curtain hanging between the product and the viewer, muffling the bright areas and illuminating the dark ones, in order to create a soft and imperceptible tone gradation. The portrait of Mona Lisa is probably the most striking example of using this method. Leonardo da Vinci wrote: "Things at a distance seem ambiguous and doubtful to you; do them with the same vagueness, otherwise they will appear in your picture at the same distance... do not limit things that are distant from the eye, because not only these boundaries, but also parts of the bodies are imperceptible at a distance." The great artist noted that the distance of an object from the observer's eye is associated with the change of the object's color. Therefore, in order to transfer the depth of space in the picture, the nearest objects must be depicted by the artist in their own colors, and the remote ones acquire a bluish overtone, "...and the furthest objects, visible in it, such as mountains due to the large amount of air between your eye and the mountain, seem blue, almost the color of the air...".

Perceptive perspective. Academician B. V. Rautenbach studied how a person perceives depth in connection with binocularity of vision, mobility of point of view and constancy of the object's form in the subconscious mind and came to the conclusion that the close-up view is perceived in reverse perspective, the shallow distant view - in axonometric perspective, the far distant view-in direct linear perspective (Fig. (2) [5]. This is a general perspective that combines a reverse, axonometric and linear perspective, called perceptive perspective [5].

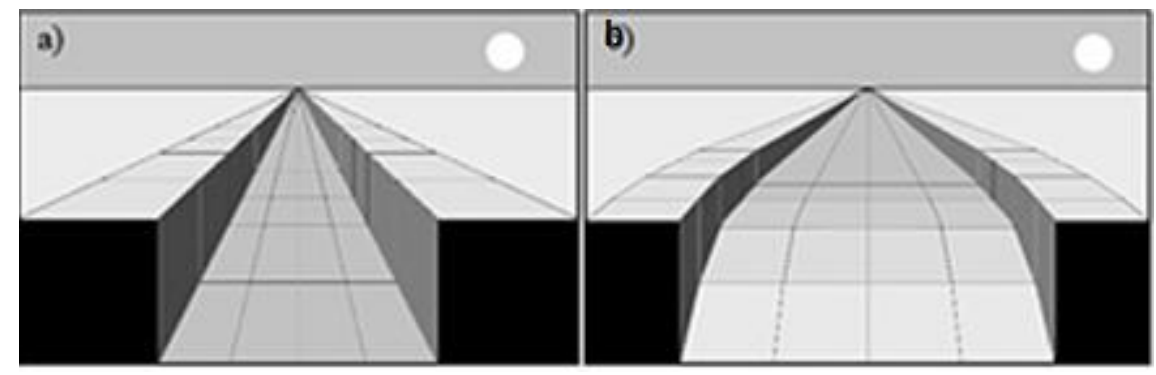

Fig. 4. $a$ - linear perspective, $b$ - perceptive perspective.

Axonometry. Axonometric images are images devoid of perspective distortions. Mathematical analysis of the equations of perceptual perspective shows that the nearest space surrounding a person, he sees under the laws of parallel perspective, that is, axonometry. Due to their precise matching with the natural visual perception, axonometric images have impressive visibility and, moreover, are easy to perform. Therefore, they are widely used in engineering drawings, when there is a need to convey the exterior of some parts without distortion.

If now, after considering all kinds of perspective constructions we return to the idea that mathematically accurate image of space on the sketch is impossible, we can say that each type of perspective has its advantages and disadvantages. Based on the same conclusions about the theory of perceptual perspective, it can be seen that for the image of deep space linear perspective should be used, for the construction of objects lying in the close-up view, one should apply the reverse perspective, for engineering drawings - axonometric perspective. Thus, when choosing a perspective, it is necessary to start from the goals and purposes. Modern architects, armed with knowledge of the theory of various perspective images, should use all the power of their spatial thinking and creative imagination to choose such 
architectural solutions at the design stage, which would consider the features of the architectural space perception of different depth. Finally, we can say that the humorous phrase" I see so " becomes reasonable, as the only model of graphic representation can be the image that our brain can see.

\section{Materials and methods}

Work on an architectural project is a long and extremely complex process. It involves many participants, among which are customers, investors, architects, builders, economists, engineers of various specialties and ultimately - users of the created architectural environment. All of them have their own unique professional language. But there are people among all these participants, around whom the design process is built, as around a certain core-and this, of course, is an architect, a person who has many professional qualities that contribute to the implementation of the general idea. These qualities allow him not only to understand the requirements and wishes of all members of the architectural process, but also to express them in graphic language, reworking and bringing to perfection [6]. Such issues as the development of qualities that contribute to becoming a professional, as well as fulfillment of his creative skills in the future profession are significant subject for researchers in various fields: teachers, psychologists, specialists in specific areas. [1].

As for students-architects' training the most important qualities for a professional architect are those that form a specialist, who is free to express his ideas and able to implement them in real projects [7]. Educational programs for architects include many disciplines, a significant part of which is associated with the education of graphic culture. As a result of the training students develop the following skills and abilities: skills of graphic techniques; an understanding of the projection matter of images [8]; the features of visual perception of spatial objects 2 [9]. The qualities that an architect should have at different stages of his professional life are quite diverse. [6]. In order to study the opinion of professional architects and students-architects on how they see an "ideal" architect and "ideal" studentarchitect, preliminary surveys were conducted, where practicing architects, teachers and students of the faculty of architecture of SP SUACE appeared as the experts. 21 characteristics were selected as necessary, according to respondents' opinion, for successful learning (the image of a student-architect) and professional work (the image of an architect). The analysis of the revealed characteristics allowed to combine them into three groups of qualities: professional, creative, personal. Further, two lists of qualities for an "ideal student" and "successful architect" were formed. Respondents were asked to rank qualities from one list in order of importance for the "ideal student" and from another list for the "successful architect". The hypothesis was the assumption that creative abilities are amongst the most important professional qualities for both practicing architects and students - architects, but the significance of some of them may change on the way of mastering the profession. Imaginative abilities, such as creative imagination and spatial thinking are the core of the profession; without them it is impossible to carry out professional work of an architect. After processing and analyzing the empirical data, the characteristics that occupy the highest positions for each group of respondents were highlighted. The frequency mention (in \%) of these characteristics for the images of an "ideal student" and "successful architect" are presented in tables $1,2$.

Table 1 The frequency mention of significant characteristics of an "ideal student-architect's image" by different groups of respondents.

\begin{tabular}{|c|c|c|c|c|}
\hline \multirow[t]{2}{*}{ Characteristics } & \multicolumn{2}{|c|}{ Students } & \multirow{2}{*}{$\begin{array}{l}\text { Mas- } \\
\text { ters }\end{array}$} & \multirow{2}{*}{$\begin{array}{l}\text { Prac- } \\
\text { ticing } \\
\text { archi- }\end{array}$} \\
\hline & $\begin{array}{l}\text { Year } \\
2\end{array}$ & $\begin{array}{l}\text { Year } \\
5\end{array}$ & & \\
\hline
\end{tabular}




\begin{tabular}{|l|l|l|l|l|l|}
\hline \multirow{1}{*}{$1-p$} & & & & tects \\
\hline \multirow{7}{*}{$\begin{array}{l}\text { Able to navigate the flow of infor- } \\
\text { mation and highlight the important } \\
\text { aspects for this stage of training. }\end{array}$} & 20 & 31 & 70 & 98 \\
\cline { 2 - 6 } & Efficient, hardworking & 96 & 60 & 80 & 27 \\
\cline { 2 - 6 } & $\begin{array}{l}\text { Has a desire to learn; to pass exams } \\
\text { and tests on time }\end{array}$ & 66 & 27 & 25 & 25 \\
\cline { 2 - 6 } & Able to do the work on his own & 21 & 56 & 38 & 56 \\
\cline { 2 - 6 } & Intelligent & 63 & 72 & 82 & 20 \\
\hline \multirow{2}{*}{ 2-c } & Thinks creatively & 84 & 96 & 84 & 72 \\
\cline { 2 - 6 } & Has the developed imagination & 75 & 64 & 70 & 58 \\
\hline
\end{tabular}

Table 2 The frequency mention of significant characteristics of a "successful professional architect's image" by different groups of respondents.

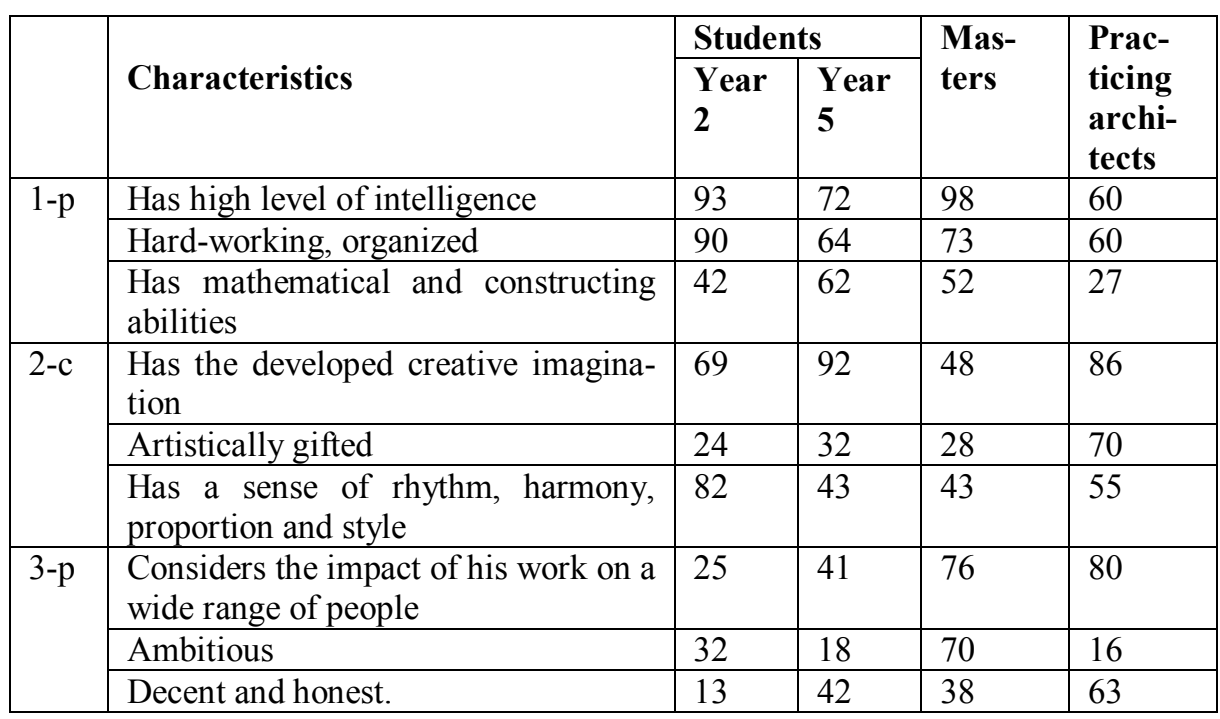

Keys: 1-p - professional characteristics; 2-c -creative characteristics; $3-p-$ personality characteristics.

\section{Result and Discussion}

As it can be seen from table 1, all groups of respondents assigned high ranks to imagination and creative thinking. Training and intellectual characteristics also have high ranks. There is a certain fading of interest in learning over time, but the increasing importance of the ability to perform work independently and navigate the flow of information, which is especially emphasized by practicing architects [6].

From table 2 it can be seen that along with intellectual abilities, the fifth-year students and practicing architects mark high ranks for creative characteristics. At the same time, practicing architects note the high importance of both developed creative imagination and responsibility for the consequences of their own work for a wide range of people. Students also attribute high ranks to those characteristics that contribute to a good, creative work performance. Thus, according to students, the most important qualities are the abilities that 
ensure the quality of design work, while practicing architects emphasize the characteristics that are important for the quality of their work outcome (the impact on society) [6].

While processing the results, it was noted that in both cases the dominating quality is developed imagination, which is one of the determining characteristics in such a complex and versatile profession [6].

People of different professions have various propensities and level of imagination. If at the lower levels of imagination, the processes take place automatically, by themselves, then at the higher levels the conscious, active attitude to the formation of images plays a leading role. By the nature of images that imagination operates, abstract and concrete imagination are distinguished. Images of high generality, having common features, belong to the abstract imagination. Its characteristic features are the following: graphic interpretation of images, formation of images, modeling elements and research areas that correspond to certain tasks of work or learning. Thus, the abstract imagination is realized in the form of such images as diagrams and drawings, and in mathematics - symbols, formulas, diagrams [10]. Many mathematicians, judging by their statements, given the high degree of their science' abstraction, tend to use graphic images and express the problem under study geometrically. Academician A. D. Alexandrov pointed out that geometry combines vivid imagination and strict logic, while they mutually organize and direct each other. "Imagination gives a direct vision of a geometric fact and prompts logic its expression and proof, and logic, in turn, gives accuracy to the imagination and directs it to creation of pictures that reveal the connections which are necessary for logic " [11].

\section{Conclusion}

Methods of teaching descriptive geometry to future architects should be based on the development of abstract imagination, spatial and creative thinking, the use of applied nature of the discipline and formation of professional focus on future architectural work. Teaching descriptive geometry is a fundamental graphic training of students-architects, providing the basic professional level of graphic knowledge and skills. The development of spatial thinking should be based on the study of three-dimensional objects' formation and their characteristics, as well as graphic methods and ways of their representation on the sketch, the transformation of the objects' shape. This requires knowledge of the basic theoretical principles, graphic methods and methods of construction, the study of the properties of the three-dimensional world's objects. It is also necessary to have a clear understanding of the practical purpose of the graphic language as a language of scientific and technical communication, which allows to operate with spatial images of various objects.

Among the disciplines that form the necessary competence of future architects, there is one that helps to develop existing cognitive and imaginative abilities, it is descriptive geometry. The basic geometric images used in this discipline are abstract elements: a point, a line and a surface, which allows you to mark its abstract entity. Solving the positional and metric problems, in addition to the use of logical algorithms of descriptive geometry, it is required to connect the ability of spatial representations, since the inadequacy of orthogonal drawings makes it difficult to solve them. The possibility of mental spatial transformations, the use of creative imagination and spatial thinking allows to imagine the problem figuratively, to determine the sequence of actions and to choose the algorithm of the solution.

\section{References}

1. Masters of architecture about architecture, $591 \mathrm{pp}$. (Moscow, Art, 1972)

2. V. L. Glazychev, Origin of architecture, 126 pp. (Moscow, Stroyizdat, 1983) 
3. A.V. Stepanov, G.I. Ivanova, N.N. Nechayev, Architecture and psychology: manual for the academic bachelor degree 2nd prod, $355 \mathrm{pp}$. (Moscow, Yurayt publishing house, 2018)

4. L. A. Maslova, An open-air for architects 92 pp. (Ukhta, UGTU, 2007)

5. B. V. Rautenbach, The systems of prospect in the fine arts, General theory of prospect (Moscow, Science, 1986)

6. O. V. Melnikova, Some features of the creative thinking of students of architectural and construction professions, Bulletin of Civil Engineers, 6(41), pp. 346-353 (2013)

7. S. Bradley, G. Woodling, Accommodating future business intelligence: new work-space and work-time challenges for management and design Facilities, 18:3/4, pp. 162-167 (2000)

8. T. J. L.Van Rompay, M. Veltkamp, A. T. H. Pruyn, A view from the inside: Perspective taking in object perception. Sensoria-A Journal of Mind, Brain, and Culture, 10(1), 34-40 pp. (2014)

9. W. Wrennall, Facilities design for an integrated structure Work Study, 48:4, pp.123-130 (1999)

10. S. Lacey, C. Campbell, K. Sathian, Vision and touch: Multiple or multisensory representations of objects? Perception, 36, 1513-1521 (2007)

11. A. D. Alexandrov, A. L. Verner, V. I. Ryzhik, L. P. Evstafieva, Geometry, 10-11 class Guidelines (2013)

12. K. Alexander, Facilities management: theory and practice E \& F N Spon (1996)

13. T. J. L. Van Rompay, M. Veltkamp, A. T. H. Pruyn, A view from the inside: Perspective taking in object perception. Sensoria-A Journal of Mind, Brain, and Culture, 10(1), pp. 34-40 (2014)

14. L. E. Janlert, E. Stolterman, The character of things. Design Studies, 18(3), pp. 297-314 (1997)

15. O. V. Melnikova, Research of representations of students of professionally important qualities of the architect, Proceedings of the Russian State Pedagogical University named after A. I. Herzen, 164, pp. 221-225 (St. Petersburg, 2014)

16. A. V. Petrovskiy, M. G. Yaroshevskiy, p 30 Psychology: Textbook for students of higher pedagogic institutions, 2nd edition, stereotype, 512 pp. (Moscow, Publishing Center "Academy", Higher school, 2003)

17. S. Lacey, C. Campbell, K. Sathian, Vision and touch: Multiple or multisensory representations of objects? Perception, 36, pp. 1513-1521 (2007)

18. I. Rock, Introduction to the visual perception (Moscow, 1980)

19. R. L. Solso, Cognitive Psychology (Moscow, 1996)

20. L. S. Rubinstein, Fundamentals of general psychology. 2nd edition, 720 p. (SaintPetersburg, 2002)

21. Journal for Geometry and Graphics. Volume 5, 1, pp. 23-33 (2001)

22. J. Piaget, How children form mathematical concepts, Questions of Psychology in 1966, 4 